\title{
Antioxidant and Immunotropic Properties of some Lithium Salts
}

\author{
Evgenii Plotnikov $^{1}$,Olesya Voronova ${ }^{1}$, Wolfgang Linert ${ }^{2}$, Dmitrii Martemianov ${ }^{1}$, Elena Korotkova ${ }^{1}$, Elena Dorozhko ${ }^{1}$, \\ Anna Astashkina ${ }^{1}$, Irina Martemianova ${ }^{1}$, Svetlana Ivanova ${ }^{3}$, Nikolay Bokhan ${ }^{3}$ \\ ${ }^{1}$ Tomsk Polytechnic University, 634050, Tomsk, Lenin av., 30, Russia. ${ }^{2}$ Institute of Applied Synthetic Chemistry, Vienna University of Technology, \\ Getreidemarkt 9/163-AC, A-1060 Vienna, Austria. ${ }^{3}$ Mental Health Research Institute, Tomsk, Aleutskaya 4, Russia.
}

\begin{tabular}{l} 
ARTICLE INFO \\
\hline Article history: \\
Received on: 18/09/2015 \\
Revised on: 08/11/2015 \\
Accepted on: 04/12/2015 \\
Available online: 26/01/2016 \\
\hline Key words: Antioxidant \\
Activity; immunotropic \\
effects; voltammetry; \\
phagocytosis; RBTL; mental \\
diseases; lithium glutamate; \\
lithium salicylate; lithium \\
benzoate; lithium lactate.
\end{tabular}

\section{INTRODUCTION}

Lithium is well-known and widely used in medicine element, first of all, for treatment of bipolar disorder. However, all lithium potential and benefits for human health have not been fully realized yet. Interest in lithium for the prophylaxis of depression was growing apace (Shorter, 2009), lithium is an effective treatment for reducing the risk of suicide (Cipriani et al., 2013). A number of controlled lithium trials in mania proven effectiveness of therapy. Naturally occurring element, lithium provides a high quality, efficient treatment. Lithium is proved to be effective in the prevention of Alzheimer's disease (Forlenza et al., 2011). Lithium is also of interest as a prophylactic agent in addictive pathologies, in particular alcoholism. Second generation anticonvulsants carbamazepine and valproate are now widely used as alternatives or adjuncts to lithium; despite this lithium is gold standard for bipolar treatment until now. Lithium has a relatively narrow therapeutic index and causes poisoning (Maj, 2003). Therapeutic level of lithium in blood equal $0.6 \mathrm{mmol} / \mathrm{L}$ for psychoses treatment, but side effect can occur at levels equal $1.2 \mathrm{mmol} / \mathrm{L}$ and more.

\footnotetext{
* Corresponding Author

Evgenii Plotnikov, Physical and analytical chemistry department, Tomsk polytechnic university, Tomsk, Russia.Email:plotnikov.e@mail.ru
}

Lithium levels must be carefully monitored to avoid toxic side effects. Lithium side effects can include gastrointestinal distress, increased thirst, and water retention, outbreaks of acne, minor hand or arm tremors, and increased frequency of urination. Overall toxicity of the drug is determined by the properties of lithium anionic component, not only lithium ions. Correct selection of the anionic component of the lithium salt allows to give new desirable properties and to reduce side effects. It is important to note, many pathological processes are accompanied with oxidative stress and immune insufficiency. From this point of view, it is very topical to create prospective lithium medicine with antioxidant and immunotropic properties that can reduce side effect and reinforce nonspecific resistivity.

As a rule, mental diseases assume long medicinal therapy, so reducing side effects become one of the most important problems. Designing of promising lithium preparations antioxidant and immunomodulatory properties makes it possible to affect multiple pathogenesis links. In particular, this is important in the therapy of mental disorders ( $\mathrm{Ng}$ et al., 2008). Important role of free radicals is established in the pathogenesis of schizophrenia (Reddy et al., 1996). Antioxidant enzymes (superoxide dismutase, SOD; glutathione peroxidase, GSHPx; and catalase, CAT) which are constitutively expressed in all tissues are found to be altered in erythrocytes of schizophrenic patients (Mahadik et al., 1996). 
Previous studies of antioxidant activity (Korotkova et al., 2011) of the human blood confirmed an exhaustion of antioxidant protective systems of patients affected by the mental diseases (Korotkova et al., 2013). Here we investigated some lithium salt for antioxidant properties (based on electrochemical processes) according to procedure (Avramchik et al., 2005) and immunomodulatory properties (based on influence on neutrophils and lymphocytes of human blood in vitro).

\section{MATERIALS AND METHODS}

The following lithium compounds have been used for the research: lithium glutamate, lithium salicylate, lithium benzoate and lithium lactate (fig. 1).

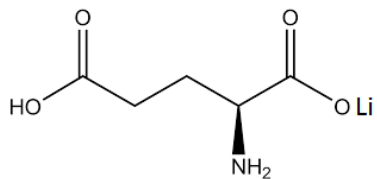

lithium glutamate

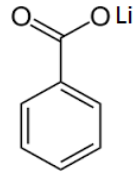

lithium benzoate

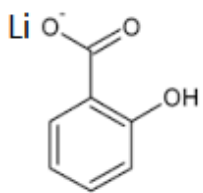

lithium salicylate

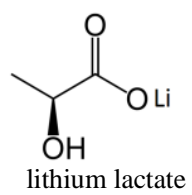

Fig. 1: Formulas of investigated lithium salts.

Stock solutions of lithium salts were prepared in the distilled water. These solutions were diluted to the working concentration after mixing with phosphate buffer $0.025 \mathrm{~mol} \cdot \mathrm{l}^{-1}$ (equimolar mixture of $\mathrm{Na}_{2} \mathrm{HPO}_{4}$ and $\mathrm{KH}_{2} \mathrm{PO}_{4}, \mathrm{pH}$ 6.86), which was used as a supporting electrolyte for voltammetry analysis.

\section{Detection of antioxidant activity by voltammetry}

The automated voltammetric analyzer "TA-2" ("Tomanalyt", Tomsk, Russia) with three-electrode open electrochemical cell was used for antioxidant activity detection. The electrochemical oxygen reduction $\left(\mathrm{ER} \mathrm{O}_{2}\right)$ at working mercury film electrode progresses at several stages with the formation of the reactive oxygen species (ROS), such as $\mathrm{O}_{2}{ }^{\circ}-$. This process is similar to the oxygen reduction in the tissues of a living organism. The measurement includes the recording current of the cathodic reduction of oxygen with and without the investigated compounds under the following conditions: potential rate scan $0.03 \mathrm{~V} \mathrm{~s}^{-1}$, potential range from $0.0 \mathrm{~V}$ to $-0.8 \mathrm{~V}$, amplitude $10 \mathrm{mV}$. All tested substances were added in the electrochemical cell in volume $0.1 \mathrm{ml}$. The following concentrations were chosen for more objective comparison in this test: equal-mass concentrations for all samples $0.5 \mathrm{mg} / \mathrm{ml}$; equal-molar concentrations 1.36 $\mu \mathrm{mol} / \mathrm{ml}$, this concentration for lithium ions may be considered as toxic level for medical application; the concentrations corresponding to therapeutic concentrations of lithium in the blood of patients $\left(0.6 \mu \mathrm{mol} / \mathrm{ml}\right.$ of $\mathrm{Li}^{+}$ions recalculated to substance weight). The last dosage is more important for comparison from medical point of view.

Antioxidants react with ROS and decrease of ROS concentration at the electrode. The current of ER $\mathrm{O}_{2}$ decreases accordingly. Detailed scheme of these interactions has been previously described (Tur'yan et al., 2004). Coefficient of antioxidant activity of the substances, $\mathrm{K}$, in $\mu \mathrm{mol}^{1} \mathrm{l}^{-1} \mathrm{~min}^{-1}$, reflects the amount of active oxygen radicals being scavenged by the antioxidants within certain time, according to the formula 1 .

$$
K=\left(1-\frac{I}{I o}\right) \times\left(\frac{C o}{t}\right)
$$

Where $C_{0}\left[\mu \mathrm{mol} \cdot \mathrm{l}^{-1}\right]$ is the oxygen concentration in solution, $I$ is the ER $\mathrm{O}_{2}$ current with the investigated substance addition in the solution, $I_{o}$ is the limiting ER $\mathrm{O}_{2}$ current without the substance in the solution, $t$ ( $\mathrm{min}$ ) is time of the interaction between the reactive oxygen species and an antioxidant at the working electrode.

\section{Influence of lithium compounds in the reaction of blastic transformation of lymphocytes}

Measurement of proliferative responses of human lymphocytes allows estimating biological responses of immune cells before and after the addition of a stimulating agent. The method is based on phytohemagglutinin (PHA) - induced proliferative response of the lymphocytes. The blood samples obtained from healthy donors. Lymphocytes were isolated by gradient centrifugation and re-suspended with RPMI 1640, containing $20 \%$ fetal bovine serum, L-glutamine, streptomycin. Aliquots of $0.1 \mathrm{ml}\left(2 \times 10^{6}\right.$ cells $\left./ \mathrm{ml}\right)$ of the mixture were placed in a separate microculture plates. Substances were added to plate in two concentrations, first, equal-molar - all samples were in concentration $1.36 \mu \mathrm{mol} / \mathrm{ml}$ and in concentrations corresponding to therapeutic concentrations of lithium in the blood of patients ( $0.6 \mu \mathrm{mol} / \mathrm{ml}$ of $\mathrm{Li}^{+}$ions recalculated to substance weight). All procedures repeated with and without PHA. Control group was without substances. Culture plates were sealed and incubated for 72 hours at $37^{\circ} \mathrm{C}$. Lymphocyte transformation was detected by method (Goldberg et al., 1992).

\section{Influence of lithium compounds on phagocytic activity of leucocytes}

The phagocytic activity of the neutrophils was studied using phagocytosis method (Novikov, 1996). The Gram-positive bacteria, Staphylococcus aureus - H209, were used as the phagocytic substrate. Staphylococcus aureus was added to the leukocyte suspension obtained from the human blood. The investigated substances were added to the microculture plates in different concentration $(0.1-0.001 \mathrm{mg} / \mathrm{ml})$. The phagocytic index was calculated as the number of neutrophils positive for $S$. aureus ingestion per 100 neutrophils. The avidity index was calculated as the total number of $S$. aureus cells engulfed per 100 positive neutrophils and divided by 100 . The index of phagocytosis completeness was calculated as the number of $S$. aureus killed in phagocytes divided by the total number of the microbes engulfed by phagocytes per 100 . 


\section{Statistical Analysis}

Statistical analysis was performed using Statistica 6.0 software. The mean changes in coefficients of antioxidant activity and cell influences of tested substances were calculated after triple experiments. Data are presented as mean $\pm \mathrm{SD}$.

\section{RESULTS}

Mean coefficients of antioxidant activity for all substances are evaluated and shown in table 1. Coefficient $\mathrm{K}$ reflects interaction between oxygen radicals and antioxidant, otherwise velocity of radicals scavenging.

Table 1: Antioxidant activity coefficients of the investigated lithium salts.

\begin{tabular}{|c|c|c|c|}
\hline \multirow[b]{2}{*}{ Substance name } & \multicolumn{3}{|c|}{ Antioxidant activity coefficient, $\mathrm{K}\left(\mu \mathrm{mol} \mathrm{I}^{-1} \mathrm{~min}^{-1}\right)$} \\
\hline & $\begin{array}{c}\text { (equal-mass), } \\
0.5 \mathrm{mg} / \mathrm{ml}\end{array}$ & $\begin{array}{c}C \text { (equal-molar), } \\
1.36 \mu \mathrm{mol} / \mathrm{ml}\end{array}$ & $\begin{array}{l}C \text { (therapeutic) } \\
\mathrm{Li}^{+} 0.6 \mu \mathrm{mol} / \mathrm{ml}\end{array}$ \\
\hline Lithium & $0.45 \pm 0.07$ & $0.23 \pm 0.07$ & $0.17 \pm 0.06$ \\
\hline Lithium salicylate & $0.33 \pm 0.06$ & $0.31 \pm 0.09$ & $0.20 \pm 0.11$ \\
\hline Lithium benzoate & $0.53 \pm 0.06$ & $0.37 \pm 0.09$ & $0.14 \pm 0.07$ \\
\hline Lithium lactate & $0.19 \pm 0.06$ & $0.18 \pm 0.06$ & $0.11 \pm 0.06$ \\
\hline
\end{tabular}

Table 2: Lithium compounds influence on lymphocytes proliferation.

\begin{tabular}{lcccc}
\hline \multicolumn{1}{c}{ Substance } & \multicolumn{2}{l}{$\begin{array}{l}\text { lymphocytes proliferation } \\
\text { without PHA, percentage }\end{array}$} & $\begin{array}{c}\text { PHA - induced proliferation } \\
\text { of lymphocytes, percentage }\end{array}$ \\
\hline & Control & $\begin{array}{c}C \text { (therapeutic) } \\
\mathrm{Li}^{+} 0.6 \mu \mathrm{mol} / \mathrm{ml}\end{array}$ & Control & $\begin{array}{c}\mathrm{C} \text { (therapeutic) } \\
\mathrm{Li}^{+} 0.6 \mu \mathrm{mol} / \mathrm{ml}\end{array}$ \\
\hline Lithium glutamate & $6 \pm 0.5 \%$ & $6 \pm 2.0 \%$ & $87 \pm 2.5 \%$ & $91 \pm 4.5 \%$ \\
Lithium salicylate & $6 \pm 0.5 \%$ & $6 \pm 1.5 \%$ & $87 \pm 2.5 \%$ & $84 \pm 6.0 \%$ \\
Lithium benzoate & $6 \pm 0.5 \%$ & $12 \pm 3.0 \%$ & $87 \pm 2.5 \%$ & $95 \pm 5.0 \%$ \\
Lithium lactate & $6 \pm 0.5 \%$ & $7 \pm 1.0 \%$ & $87 \pm 2.5 \%$ & $92 \pm 4.5 \%$ \\
\hline
\end{tabular}

Results of the influence of lithium compounds on immune blood cells "in vitro" (reaction of blastic transformation of lymphocytes) are presented in the table 2. There are no significant effects on RBTL are shown for lithium glutamate and salicylate. Lithium benzoate expressed stimulating influence on proliferation with and without PHA.

Table 3: Influence of lithium salts on neutrophils phagocytic activity (all tested substances are in equal concentration $0.6 \mu \mathrm{mol} / \mathrm{ml} \mathrm{Li}+$ ions)

\begin{tabular}{|c|c|c|c|c|c|}
\hline Indicator & 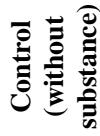 & 苞 & 志晜 & 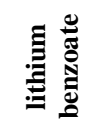 & 四 \\
\hline $\begin{array}{l}\text { Active phagocytosis } \\
\text { percentage }\end{array}$ & $50 \pm 4 \%$ & $48 \pm 7 \%$ & $50 \pm 7 \%$ & $52 \pm 5 \%$ & $34 \pm 8 \%$ \\
\hline $\begin{array}{l}\text { Avidity index } \\
\text { (bacteria/phagocyte) }\end{array}$ & $12 \pm 3$ & $13 \pm 5$ & $10 \pm 4$ & $11 \pm 3$ & $10 \pm 4$ \\
\hline $\begin{array}{l}\text { Percentage of } \\
\text { phagocytosis } \\
\text { completeness }\end{array}$ & $61 \pm 5 \%$ & $60 \pm 7 \%$ & $72 \pm 7 \%$ & $70 \pm 6 \%$ & $69 \pm 7 \%$ \\
\hline
\end{tabular}

Insignificant stimulation activity was shown for lithium lactate. No suppression activity on lymphocytes proliferation was detected for all substances. Immune cell influence of lithium compounds, indicated by the phagocytic activity of neutrophilic leucocytes "in vitro" are presented in the Table 3. The most significant influence on phagocytosis completeness revealed for lithium salicylate, benzoate and lactate. Meanwhile, lithium glutamate has no significant influence for all parameters. Lithium lactate revealed slight suppressive influence on phagocytosis activeness; other salts did not suppress any phagocytosis parameter.

\section{DISCUSSION}

Study antioxidant properties in equal-mass concentration revealed the best comparative antioxidant properties of lithium benzoate and glutamate. However, this parameter is twice less than that one of widely used antioxidant - ascorbic acid with coefficient $\mathrm{K}$ of $1.15 \mu \mathrm{mol}{ }^{-1} \mathrm{~min}^{-1}$ in same concentration of $0.5 \mathrm{mg} / \mathrm{ml}$. In therapeutic concentration, all tested substances revealed low antioxidant properties, but significantly higher than well-known drug - lithium carbonate (Plotnikov et al., 2015). It should be noted, that lithium could provide indirect antioxidant activity, as it was shown in work (Vasconcellos et al., 2006) and concluded lithium presented antioxidant properties, but did not prevent stressinduced oxidative damage.

Immunotropic properties for all substances were evaluated at therapeutic concentration (according to lithium ions for bipolar psychosis treatment $0.005-0.008 \mathrm{mg} / \mathrm{ml}$, recalculated to substance weight) for easier extrapolation for possible effect in vivo.

Results in Table 2 show lithium glutamate and salicylate did not affect both spontaneous and PHA-stimulated lymphocytes proliferation. Significant increase of spontaneous and PHAstimulated blastic transformation of lymphocytes under influence of lithium benzoate can be linked with own stimulating ability of this salt, but also with specific reaction of lymphocytes to sensitizing agent. Lithium lactate increased slightly PHAstimulated blastic transformation, but, taken into account other parameters (spontaneous proliferation) it cannot be considered as significant stimulating influence on lymphocytes. According to table 2 there were no revealed suppressive or toxic influence on immune cells for all tested lithium salt overall.

As for phagocytic activity, lithium aspartate has no significant influence, neither stimulating, nor suppressive on all tested parameters. Lithium salicylate, benzoate and lactate significantly increase percentage of phagocytosis completeness (table 3). That means these salts improve ability of phagocytes to finalize lysis of engulfed bacteria. Meanwhile these substances did not change mean number of engulfed bacteria per one phagocyte. At the same time, lithium lactate slightly decreased percentage of active neutrophils, that can be explained with negative impact on the reverse reaction of lactic acid and its derivatives. Data from table 3, revealed ability of lithium salts to enhance quality of phagocytosis. This reflects improving functional activity of the neutrophils in vitro during once time impact of lithium salt, but in literature immunostimulatory effect noted for prolonged administration of lithium (Kubera et al., 1994). Thus, revealed immunomodulatory effect of lithium in vivo is mostly linked with indirect action of lithium. Further research on this topic is necessary to create and study new lithium antioxidant with 
immunotropic properties, as a base for prospective medicine for mental diseases.

\section{CONCLUSIONS}

Investigated lithium salts expressed relatively good antioxidant activity, but lower than well-known antioxidant ascorbic acid and lithium ascorbate (Plotnikov et al., 2015). All tested substances revealed immunotropic effects, except lithium glutamate. Lithium benzoate shows the most expressed stimulating effects on lymphocytes and neutrophils. Parameters of phagocytosis also increased under influence of lithium salts that can provide immune stimulating activity in vivo. Thus, all investigated substance are of interest in possible medical application in mental diseases and comorbid pathology.

\section{ACKNOWLEDGMENTS}

The study was supported by Russian Fund for Basic Research, research project No. 15-04-01110

\section{CONFLICTS OF INTEREST}

The authors declare no conflict of interest.

\section{REFERENCES}

Avramchik OA,.Korotkova EI Plotnikov EV, Lukina AN, Karbainov YA. Antioxidant and electrochemical properties of calcium and lithium ascorbates. Journal of Pharmaceutical and Biomedical Analysis, 2005; 35:1149-1154.

Cipriani A, Hawton K, Stockton S, Geddes JR. Lithium in the prevention of suicide in mood disorders: updated systematic review and meta-analysis. BMJ, 2013; 346.

Forlenza OV, Diniz BS, Radanovic M, Santos FS, Talib LL, Gattaz WF. Disease-modifying properties of long-term lithium treatment for amnestic mild cognitive impairment: randomized controlled trial. The British Journal of Psychiatry, 2011; 198 (5): 351-356.

Goldberg ED, Dygai AM, Shahov VP. Tissue culture methods in hematology. Tomsk: Publishing House of the Tomsk State University; 1992.

Korotkova EI, Freinbichler W, Linert W, Dorozhko EV, Bukkel MV, Plotnikov EV, Voronova OA. Study of total antioxidant activity of human serum blood in the pathology of alcoholism. Molecules, 2013;18(2):1811-8.
Korotkova EI, Misini B, Dorozhko EV, Bukkel MV, Plotnikov $\mathrm{EV}$, Linert W. Study of $\mathrm{OH}$ radicals in human serum blood of healthy individuals and those with pathological schizophrenia. Int J Mol Sci, 2011; 12: 401-9.

Kubera M, Bubak-Satora M, Holanb V, Krolc W, Basta-Kaim A, Roman A, Skowron-Cendrzak K, Shani J. Modulation of Cell-Mediated Immunity by Lithium Chloride. Zeitschrift für Naturforschung, 1994; 49: 679-83.

Mahadik SP, Mukherjee S. Free radical pathology and antioxidant defense in schizophrenia: a review. Schizophr Res, 1996; 19(1):1-17.

Maj M. The effect of lithium in bipolar disorder: a review of recent research evidence. Bipolar Disord, 2003; 5:180-8.

$\mathrm{Ng} \mathrm{F}$, Berk M, Dean O, Bush AI. Oxidative stress in psychiatric disorders: evidence base and therapeutic implications. Int J Neuropsychopharmacol, 2008; 11: 851-76.

Novikov DK, Novikova VA. 1996. Immune Status Assessment. Moscow: Medicine.

Plotnikov E, Korotkova E, Voronova O, Dorozhko E, Bohan N, Plotnikov S. Lithium-based antioxidants: electrochemical properties and influence on immune cells. Physiology and pharmacology, 2015; 19:107113.

Reddy RD, Yao JK. Free radical pathology in schizophrenia: a review. Prostaglandins Leukot Essent Fatty Acids, 1996; 55(1-2):33-43.

Shorter E. The history of lithium therapy. Bipolar Disord, 2009; 11( 02 2): 4-9.

Tur'yan YI, Gorenbein P, Kohen R. Theory of the oxygen voltammetric electroreduction process in the presence of an antioxidant for estimation of antioxidant activity. J Electroanal Chem, 2004; 2:183-8.

Vasconcellos AP, Nieto FB, Crema LM, Diehl LA, de Almeida LM, Prediger ME, da Rocha ER, Dalmaz C. Chronic lithium treatment has antioxidant properties but does not prevent oxidative damage induced by chronic variate stress. Neurochem Res, 2006; 31 (9):1141-51.

\section{How to cite this article:}

Plotnikov E, Voronova O, Linert W, Martemianov D, Korotkova E, Dorozhko E, Astashkina A, Martemianova I, Ivanova S, Bokhan N. Antioxidant and Immunotropic Properties of some Lithium Salts. J App Pharm Sci, 2016; 6 (01): 086-089. 